professional growth and development, and a well-organized program to introduce junior faculty to the institution's research culture could greatly improve outcomes ${ }^{4}$. Leadership development may also be useful to ensure that department chairs communicate with their faculty, particularly those that are new and inexperienced. The IO can function as a staunch advocate of efforts to improve the overall animal research program and outcomes to the benefit of faculty, staff, and the animals.

\section{Cyndi Rosenblatt, Rupak Mukherjee and Suzanne Craig* \\ Medical University of South Carolina, Charleston, SC, USA. \\ *e-mail: craigs@musc.edu}

Published online: 18 April 2019

https://doi.org/10.1038/s41684-019-0285-y
References

1. Office of Laboratory Animal Welfare, National Institutes of Health. Frequently Asked Questions, PHS Policy on Humane Care and Use of Laboratory Animals, Section D, Question \#10; https:// olaw.nih.gov/guidance/faqs\#623.

2. Institute for Laboratory Animal Research. Guide for the Care and Use of Laboratory Animals. 8th edn (National Academies Press, Washington, DC, 2011)

3. Office of Laboratory Animal Welfare, National Institutes of Health. Guidance: Significant Changes to Animal Activities. Last updated Feb 22, 2019. https://olaw.nih.gov/guidance/significantchanges.htm

4. Keyser, D. J. et al. Acad Med 83, 217-225, https://doi.org/10.1097/ ACM.0b13e318163700a (2008).

\title{
Understand before you sign
}

W hen the IACUC makes a decision regarding the use of animals in a project, finances are not considered part of the equation. The decisions are based on scientific merit. In this instance, the outcome of the rats on this study appears to be based solely on the finances available to keep the study going. It may be that the rats need to be euthanized if they cannot be used on this study or another. The decision to euthanize them isn't based on scientific merit-it is based on finances. Since the Chair was under the impression that he only approved a pilot study of 10 rats, he now refuses to pay the per diem charges on the remaining study animals. This leaves 120 rats in peril due to finances. The inherent problem stated in this scenario is removed from the protocol and IACUC itself because the protocol was appropriately reviewed and approved, and the investigator has been compliant. We were unable to find any guidance in the Guide or PHS Policy related to this situation, and there would be no need to report the incidence, assuming their OLAW assurance only covers their PHS-funded activities.

It is not uncommon for institutions to have department chairs sign off on IACUC protocols prior to submission. However, how this is interpreted needs to be clearly articulated to avoid these types of situations. For example, does chair approval acquiesce to a financial commitment for the study, scientific review, or merely that they have knowledge of the project? Upon completing the protocol for this submission, Abraham and the Chair should have compiled a summary statement that included number of animals and charges incurred. This would have made it clear what the expectations were for each entity. Since the Chair signed off on the protocol, it would be appropriate for him to continue to support Abraham's project through completion. However, this is a tricky situation since it's unlikely anyone can "force" the Chair to continue paying per diem on the 120 rats.

In the event that the Chair does refuse to continue funding the full study, Abraham has several other options potentially available:

- She could ask the Institutional Official (IO) to help fund the study; while not an outrageous request, it would also be understandable for the IO to refute the plea and instead lay responsibility on the department in question.

- She could enlist the IO or IACUC to help reach out to the Chair and explain the situation further, in hopes of changing his mind about continuing funding for the remainder of the project.

- She could look for assistance from other faculty members with financial support who could potentially collaborate with her on this study. If this occurs and there is PHS funding involved, the activities should either be congruent with the collaborator's grant award or the program officer consulted to include Abraham's activities.
- She could discuss the situation with the facility director. While it would be inappropriate to use per diem revenue from other investigators to support this project, it is not uncommon for animal care programs to be subsidized. It could be possible for the director to use some subsidized support to help Abraham.

- She could continue funding this study with personal funds.

In any of these situations, Abraham could reassess the timeline to make the study as short as possible while still meeting the research needs. If ultimately she is unable to find financial support, the rats could be transferred to different protocols, provided that what has been done to them would not impact another study. It would be a shame to euthanize these animals due to finances, and the institution should identify a means to allow this study to continue and develop polices to mitigate this situation from recurring. Similar to IACUC review of protocols, finances shouldn't dictate unnecessary animal euthanasia.

Alyssa A. Strumpf, Alexa R. Personett and Lon V. Kendall*

Laboratory Animal Resources, Colorado State University, Fort Collins, CO, USA.

*e-mail:lon.kendall@colostate.edu

Published online: 18 April 2019

https://doi.org/10.1038/s41684-019-0286-x

\section{"Not it"}

T his is an unfortunate and seemingly preventable situation that would have been helped by changes in workflow and improved communication. Since no grant funding is involved and all studies were approved by the Institutional Animal Care and Use Committee (IACUC), it does not appear that the institution has any Office of Laboratory Animal Welfare reporting requirements. However, there are clearly several immediate problems that need to be addressed and the institution requires a long-term solution to prevent a similar situation in the future. 